\title{
Perspective
}

\section{Seawater Electrolysis for Hydrogen Production: A Solution Looking for a Problem?}

M.A. Khan ${ }^{1}$, Tareq Al-Attas ${ }^{1}$, Soumyabrata Roy ${ }^{2}$, M.M. Rahman ${ }^{2}$, Noreddine Ghaffour ${ }^{3}$, Venkataraman Thangadurai ${ }^{4}$, Stephen Larter, ${ }^{5}$ Jinguang $\mathrm{Hu}^{1^{*}}$, Pulickel M. Ajayan ${ }^{2 *}$, Md Golam Kibria $^{1 *}$

${ }^{1}$ Department of Chemical and Petroleum Engineering, University of Calgary, 2500 University Drive, NW, Calgary, Alberta T2N 1N4, Canada.

${ }^{2}$ Department of Materials Science and Nano Engineering, Rice University, 6100 Main St., Houston, TX 77030, USA.

${ }^{3}$ Division of Biological and Environmental Science and Engineering (BESE), Water Desalination and Reuse Center (WDRC), King Abdullah University of Science and Technology (KAUST), Thuwal 23955-6900, Saudi Arabia.

${ }^{4}$ Department of Chemistry, University of Calgary, 2500 University Drive Northwest, T2N 1N4 Calgary, Canada.

${ }^{5}$ Department of Geosciences, University of Calgary, 2500 University Drive, NW, Calgary, Alberta T2N 1N4, Canada.

Abstract: As the price of renewable electricity continues to plummet, hydrogen $\left(\mathrm{H}_{2}\right)$ production via water electrolysis is gaining momentum globally as a route to decarbonize our energy systems. The requirement of high purity water for electrolysis as well as the widespread availability of seawater have led significant research efforts in developing direct seawater electrolysis technology for $\mathrm{H}_{2}$ production. In this Perspective, we critically assess the broad-brush arguments on the research and development (R\&D) needs for direct seawater electrolysis from energy, cost and environmental aspects. We focus in particular on a process consisting of sea water reverse osmosis (SWRO) coupled to proton exchange membrane (PEM) electrolysis. Our analysis reveals there are limited economic and environmental incentives of pursuing R\&D on today's nascent direct seawater electrolysis technology. As commercial water electrolysis requires significant amount of energy compared to SWRO, the capital and operating costs of SWRO are found to be negligible. This leads to an insignificant increase in levelized cost of $\mathrm{H}_{2}\left(<0.1 \$ / \mathrm{kg} \mathrm{H}_{2}\right)$ and $\mathrm{CO}_{2}$ emissions $(<0.1 \%)$ from a SWRO-PEM coupled process. Our analysis poses the questions: what is the future promise of direct seawater electrolysis? With an urgent need to decarbonize our energy systems, should we consider realigning our research investments? We conclude with a forward-looking perspective on future $R \& D$ priorities in desalination and electrolysis technologies.

Keywords: electrolysis; hydrogen; energy; desalination; economics

*Correspondence: jinguang.hu@ucalgary.ca, pma2@ rice.edu, md.kibria@ucalgary.ca 
Hydrogen is back in fashion as a route to decarbonize our energy systems. Globally the hydrogen market is expected to grow by $47 \%$ from 142 billion USD in 2019 to 209 billion USD in 2027. ${ }^{1}$ Since hydrogen is an energy carrier and not an energy source, it can be made dirty or clean. Today, over $95 \%$ of the 70 million tons of hydrogen produced annually comes from steam methane reforming (SMR), releasing 830 million tons of $\mathrm{CO}_{2}$ every year. ${ }^{2,3}$ While blue hydrogen routes coupling SMR to carbon capture and storage (CCS) technologies are being tested at scale ${ }^{4}$, green or sustainable hydrogen made from water electrolysis and powered by low-carbon energy is crucial to attain climate neutrality. ${ }^{2,5-7}$ As the price of renewable electricity continues to plummet, sustainable hydrogen production via water electrolysis is gaining momentum globally. ${ }^{8}$

\section{Water Electrolysis Technologies}

Today, the two main electrolyzer technologies that exist commercially are the alkaline electrolysis and proton exchange membrane (PEM) systems. Alkaline electrolysis is a mature and commercial technology, used since the 1920s, for hydrogen production in the fertilizer and chlorine industries. ${ }^{2}$ Several alkaline electrolyzers with a capacity of up to $165 \mathrm{MW}$ were built in the last century, although almost all of them were decommissioned when natural gas and SMR for hydrogen production took off in the 1970s. ${ }^{2}$ Alkaline electrolyzers are characterized by lower capital costs compared to PEM systems due to the avoidance of precious catalysts. ${ }^{9,} 10$ While alkaline electrolysis systems operate at high efficiency ( $\sim 55-70 \%$ LHV), low current density (< $0.45 \mathrm{~A} / \mathrm{cm}^{2}$ ) and low operating pressures (<30 bar) negatively impact system size and hydrogen production costs. ${ }^{11}$ Also, dynamic operation (frequent start-ups and varying power input) is limited (25-100\% of nominal load) for alkaline electrolyzers, and can negatively affect system efficiency and gas purity. ${ }^{12}$ On the other hand, PEM water electrolysis was pioneered by Grubb in the early fifties and General Electric Co. led development in 1960's to overcome the drawbacks of alkaline electrolysis. ${ }^{2}$ The PEM systems run on pure water as an electrolyte solution, and so avoid the recovery and recycling of the corrosive potassium hydroxide electrolyte that is necessary in alkaline electrolyzers. Today, industries are inclined towards PEM system due to its compact design, high system efficiency ( 52-69\% LHV) at high current density (> 1-2 A/cm²), fast response, dynamic operation (0-160\% of the nominal load), low temperatures $\left(20-80{ }^{\circ} \mathrm{C}\right)$ and the ability to produce ultrapure hydrogen at elevated pressure (30-80 bar). ${ }^{2,9,12,13}$ PEM has seen drastic 
reduction in electrolyzer stack costs over the last few years and is expected to be the dominant technology for sustainable hydrogen production by $2030 .{ }^{2,8,9}$

\section{Direct Seawater Electrolysis}

One of the requirements of PEM water electrolysis is the need of highly pure water feeds with a minimum requirement of American Society for Testing and Materials (ASTM) Type II deionized (DI) water (resistivity $>1 \mathrm{M} \Omega-\mathrm{cm}$ ) while ASTM Type I DI water $(>10 \mathrm{M} \Omega-\mathrm{cm})$ is preferred. ${ }^{14}$ ASTM defines Type II water, as required in commercial electrolyzers, as having a resistivity of $>1 \mathrm{M} \Omega-\mathrm{cm}$, sodium, and chloride content $<5 \mu \mathrm{g} / \mathrm{L}$ and $<50 \mathrm{ppb}$ of total organic carbon (TOC). ${ }^{15}$ Alkaline electrolyzers are less stringent on water quality as compared to PEM, but still needs high purity water to achieve long-term stability. Such high purity water as required by water electrolysis systems is produced through a combination of either reverse osmosis (RO), multi-stage flash distillation (MSF), electrodialysis, multiple effect distillation (MED) to desalinate water, and commonly an additional technology such as ion exchange or electrodeionization (EDI). ${ }^{16,17}$ The additional capital and operating cost associated with water purification has been the common argument that has spurred research activities into direct electrocatalysis of seawater for $\mathrm{H}_{2}$ production, with the rationale that seawater represents $\sim 96.5 \%$ of earth's water resources. ${ }^{18,19}$ A technology for direct seawater splitting could potentially be used in coastal arid zones that have limited access to freshwater yet plenty of access to seawater and renewable electricity from solar, wind and geothermal. ${ }^{19-21}$ Over the last few decades, significant research efforts have gone into direct seawater electrolysis (Figure 1). In the last decade, the field has seen 700+ scientific publications, and 340+ patent applications, which translates into millions of dollars of research funding allocated globally.

Seawater electrolysis could be done to either produce chlorine via chloride oxidation or oxygen via water oxidation. Although chlorine is a valuable industrial chemical, the quantities produced for the growing hydrogen market would far exceed global demand for $\mathrm{Cl}_{2}{ }^{22}$ Therefore, one of the major challenges has been the development of active and stable anode catalysts for selective oxygen evolution over chlorine. ${ }^{18,19}$ The competing chlorine evolution reaction (CER) is thermodynamically unfavorable compared to the oxygen evolution reaction (OER) $(\sim 480 \mathrm{mV}$ higher in alkaline media), but it is a two-electron reaction, in contrast with OER which involves four electrons. This difference in the numbers of electrons involved makes OER kinetically 
unfavorable. ${ }^{18,19,23}$ While some progress has been made on the development of selective catalysts for OER from seawater, reaching industrially relevant current densities (> $300 \mathrm{~mA} / \mathrm{cm}^{2}$ ) has been a major challenge. ${ }^{18,19}$ Even though carbonate and borate ions are present in seawater, their average concentration is too low to sustain high current densities. Majority of reports at industrially relevant current densities use seawater with a borate buffer or additives such as $\mathrm{KOH} .{ }^{18,} 19$ Furthermore, because seawater is essentially a non-buffered electrolyte, which causes a change in

$\mathrm{pH}$ near the electrode surface during electrolysis (as high as 5-9 $\mathrm{pH}$ units), leading to salt precipitation as well as catalyst and electrode degradation. ${ }^{24}$ Other challenges include the presence of other ions, bacteria, microbes, as well as small particulates, which limit the long-term stability of catalysts and membranes. ${ }^{23}$ Despite the resources and efforts that have gone into developing this technology, direct seawater splitting remains in its infancy and distant from commercialization.

\section{Desalination Technologies}

Desalination - particularly via seawater reverse osmosis (SWRO) has seen tremendous technology advancements. Over the years, with improvement of membrane technology, more efficient energy recovery devices, and process optimization of reverse osmosis (RO) systems, have resulted in lowering the energy requirements, capital (CAPEX) and operating costs (OPEX) associated with the technology. In the last few decades, the energy requirement of SWRO desalination plants has decreased from $\sim 9-10 \mathrm{kWh} / \mathrm{m}^{3}$ to $<3 \mathrm{kWh} / \mathrm{m}^{3}$ currently. ${ }^{25,}{ }^{26}$ This has led to a decrease in levelized cost of SWRO desalinated water from $>2.2 \$ / \mathrm{m}^{3}$ to $<0.6 \$ / \mathrm{m}^{3} 27$ and resulted in a 6.5-fold increase in global desalination capacity (Figure 2). As of 2020, total production capacity reached $>100$ million $\mathrm{m}^{3} /$ day, $\sim 70 \%$ of which is based on RO. The increase in production capacity is expected to follow the same trend in the next decades, as per planned and under construction plants. ${ }^{27-32}$ This raises the questions: what is the future promise of direct seawater splitting as compared to SWRO coupled with commercial water electrolysis for widespread implementation ? Further, with an urgent need to decarbonize our energy systems, should we consider realigning research priorities to disrupt the current fossil-fuel based carbon economy? 

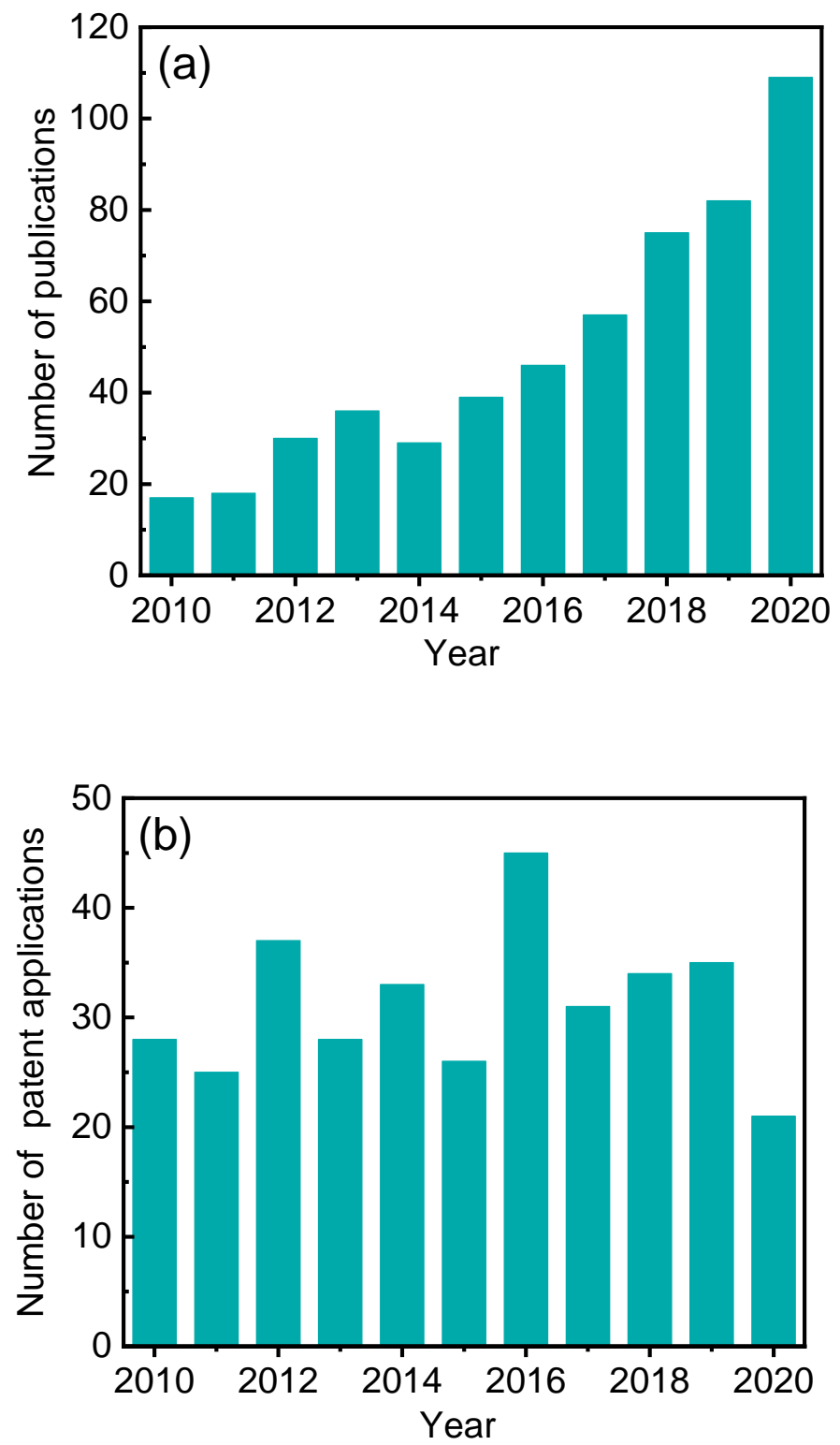

Figure 1. (a) Annual number of publications extracted from https://www.dimensions.ai/, when a search for the topic "seawater splitting" was performed. (b) Annual number of patent applications found in Patsnap database (https://www.patsnap.com/), when a search for the topic i.e., "seawater" and "electrolysis" was performed in the title, abstract or claims. 

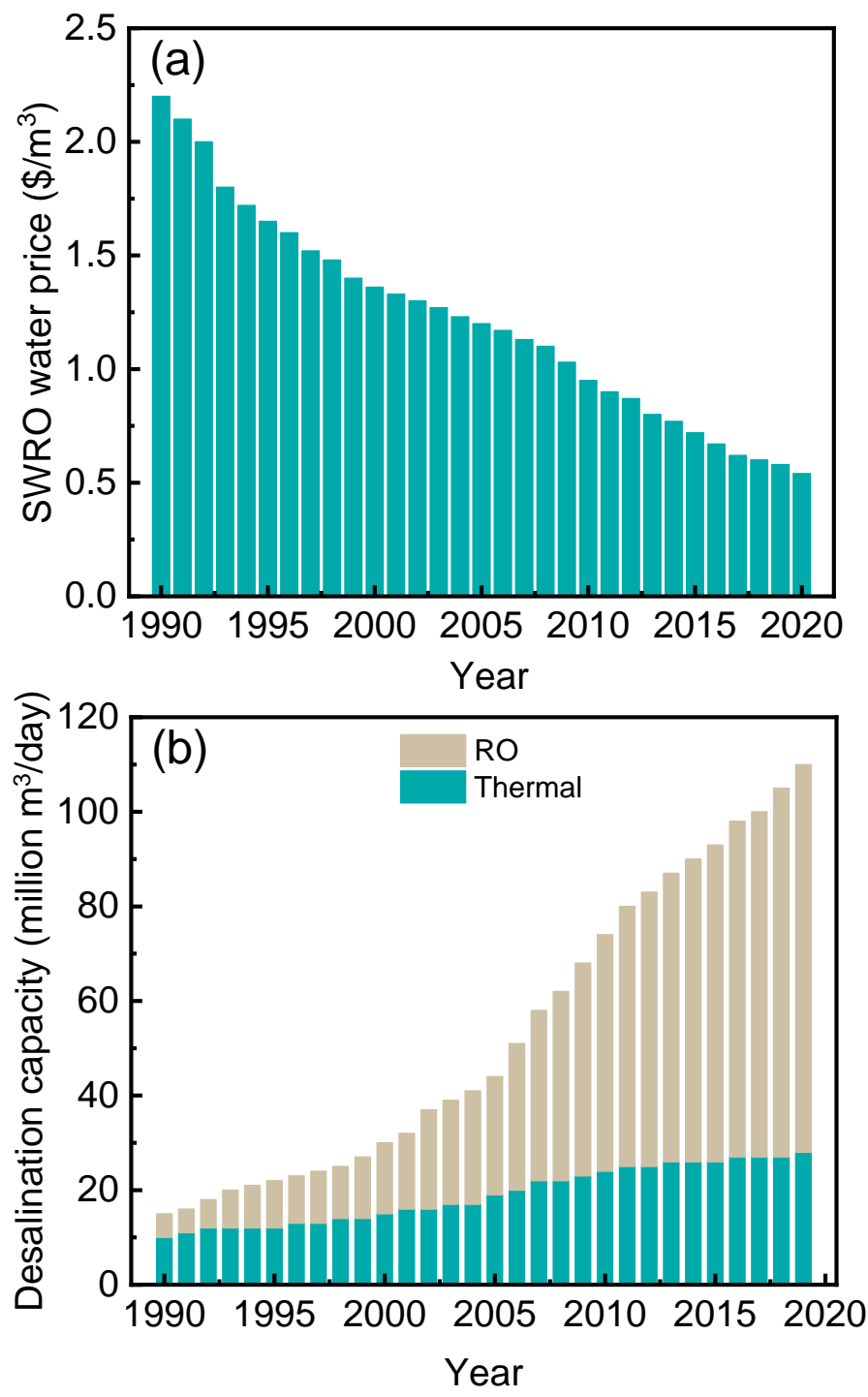

Figure 2. (a) The declining trend of SWRO desalinated water price ${ }^{27-29,33}$ and (b) annual global installed capacity of reverse osmosis (RO) and thermal desalination process ${ }^{27-30}$ 


\section{Sea Water Reverse Osmosis Coupled with Water Electrolysis}

In this viewpoint, we sought to address these questions by presenting a case study of a PEM water electrolysis system for 50 tons/day $\mathrm{H}_{2}$ production capability coupled to a SWRO plant for its water feed (Figure 3). The process is powered by the grid, which sources electricity from both fossil and renewable sources. We analyze both the economic and environmental feasibility of using SWRO water for PEM water electrolysis. As shown in Figure 3, PEM electrolysis plant consists of the electrolyzer stacks and the mechanical and electrical balance of plant (BoP) components. ${ }^{34}$ The electrical BoP consists of the AC to DC rectifier for converting grid electricity while the mechanical BoP consists of other auxiliary components such as pumps, heat exchangers, temperature swing adsorption (TSA) subsystem and most importantly a deionizer (DI) system. ${ }^{34}$

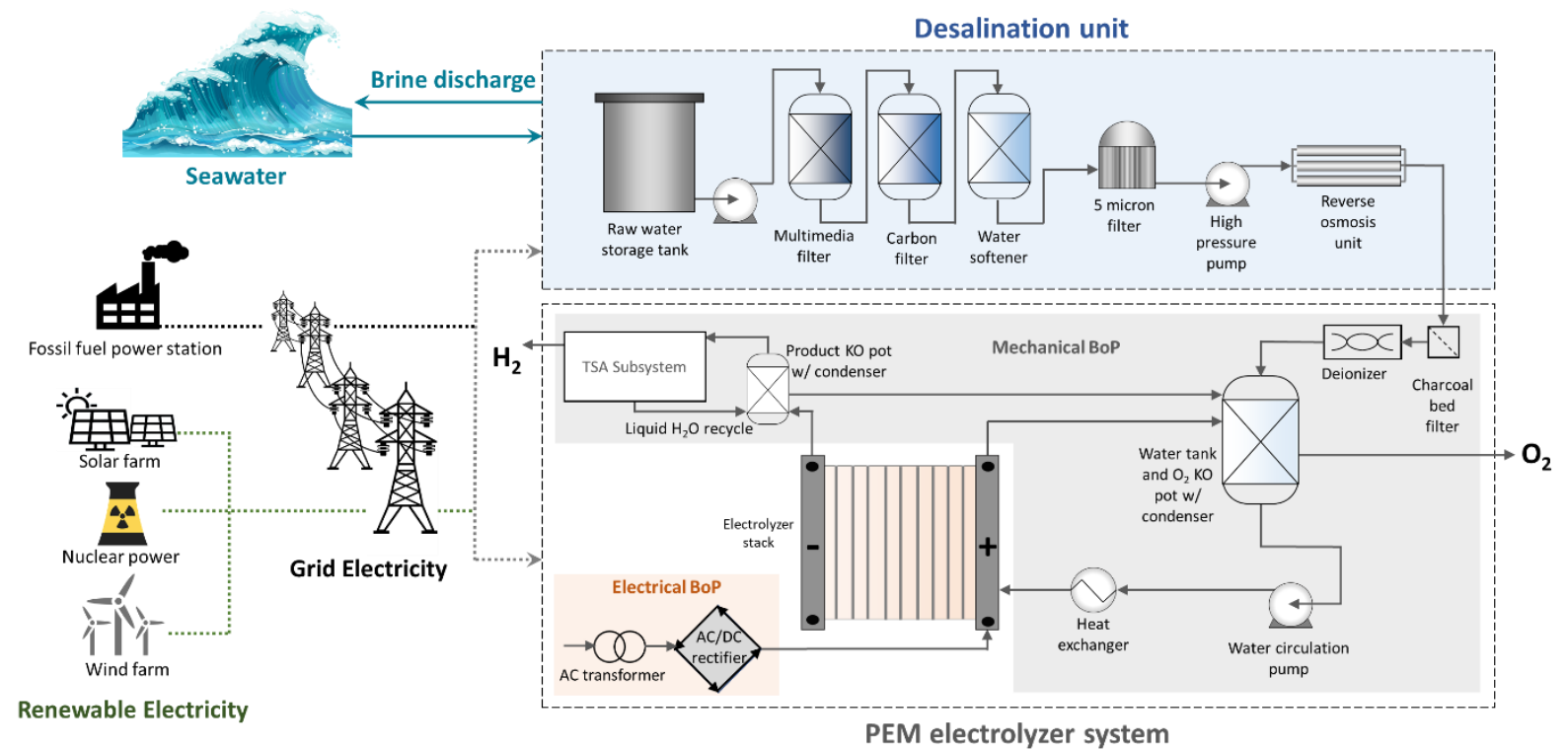

Figure 3. Schematic of grid-powered SWRO-PEM system for 50 tons/day hydrogen production. The design of SWRO and PEM systems are adapted from references ${ }^{34,35}$.

The SWRO plant contains the RO unit which uses a membrane barrier and pumping energy to separate salts from saline water. Using high-pressure pumps, water is forced through semipermeable membranes that have a dense separation layer (thin film composite membrane) allowing the passage of pure water molecules while rejecting dissolved salts and other impurities. ${ }^{36}$ In addition, in order to control RO membrane (bio)fouling and scaling, the SWRO system 
necessitates physical (e.g., dual media, sediment and carbon filters or low-pressure membranes) and chemical (e.g., coagulant polymer, antiscalant, acid, chlorination/dechlorination) pretreatment steps with variable complexity depending on raw feed water quality. ${ }^{37}$ A combination of these filters provides a broad spectrum of reduction. The carbon filters remove volatile organic compounds (VOCs), chlorine (not tolerated by polyamide RO membranes) and other contaminants that give water a bad taste or odor, sediment filter removes dirt, colloidal matter and debris while the RO membranes remove $>99.8 \%$ of total dissolved solids (TDS). ${ }^{38}$ The SWRO-PEM coupled system could be located near coastal regions with intense solar irradiation and wind patterns to produce renewable electricity using photovoltaics or wind turbines or even offshore structures if hydrogen supply for shipping for example was desired.. With ample access to seawater such regions are already equipped with large desalination plants, as shown in Figure 4, making it feasible to couple RO technology to PEM water electrolyzers. Not surprising, such locations have also been identified as potential locations for implementation of direct seawater electrolysis if and when the technology can be commercialized in future. ${ }^{19}$

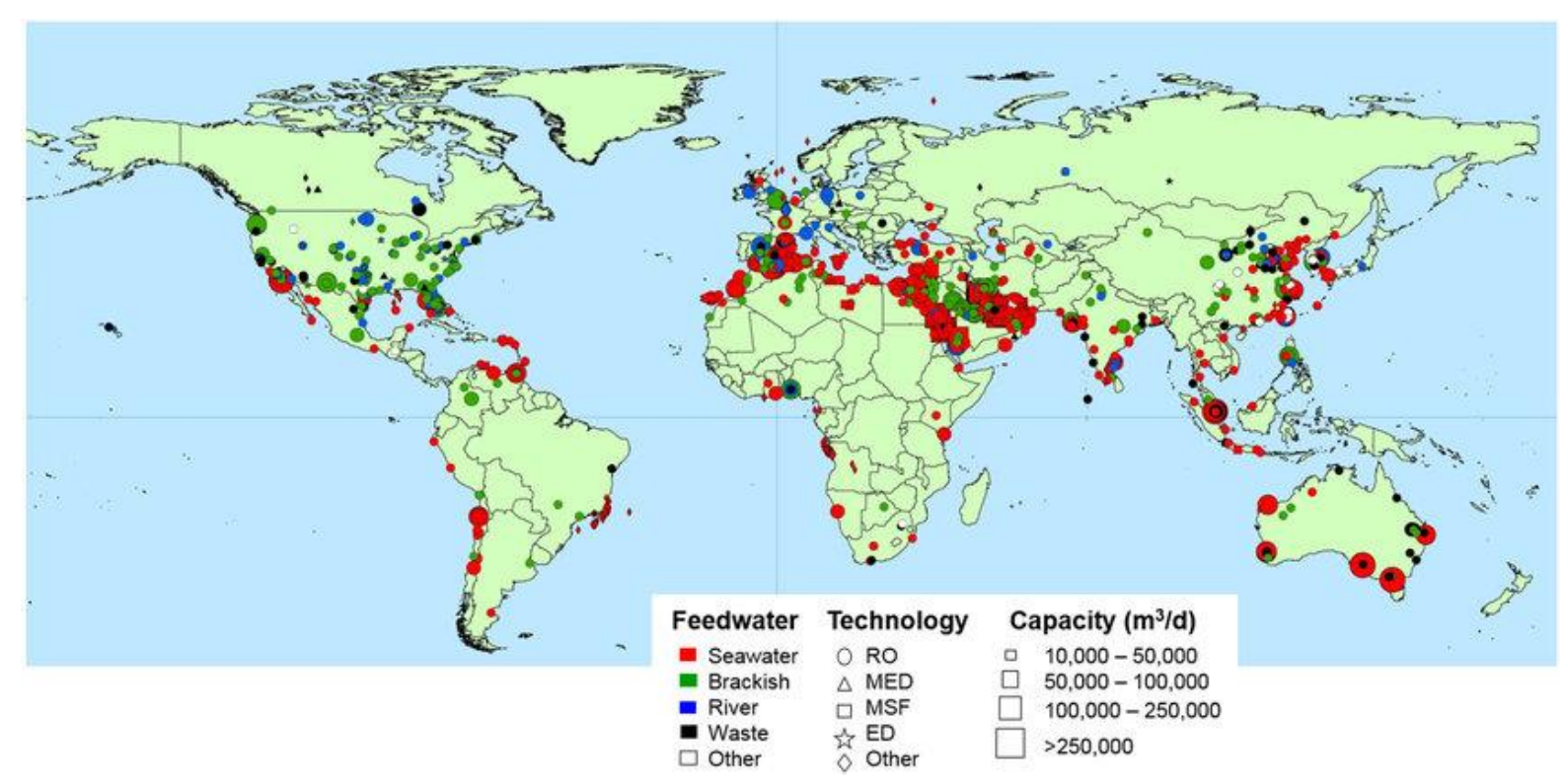

Figure 4. Global distribution of large desalination plants by capacity, feedwater type and desalination technology. Reproduced with permission from Reference ${ }^{39}$. 
PEM electrolysis plants typically need $\sim 10 \mathrm{~kg}$ water to produce $1 \mathrm{~kg} \mathrm{H}_{2}$, that is total water requirement of $500 \mathrm{~m}^{3} /$ day of $\mathrm{SWRO}$ water for 50 tons/day $\mathrm{H}_{2}$ PEM plant. ${ }^{2}$ The breakdown of the daily energy required by a coupled SWRO-PEM process is shown in Figure 5(a), highlighting the low energy ( $0.1 \%$ of total energy) required by SWRO. This is a direct result of the energy intensive water electrolysis process, with $\sim 55.44 \mathrm{kWh}$ energy (including BoP) needed to electrolyze $10 \mathrm{~kg}$ water versus only $0.03 \mathrm{kWh}$ to desalinate same amount of water. ${ }^{25,26,34}$ A breakdown of the CAPEX associated with building a SWRO-PEM plant is shown in Figure 5(b). The most comprehensive cost analysis on PEM electrolyzer systems was recently published by the U.S. Department of Energy (DOE) with the parameters summarized in Table S1. ${ }^{34}$ For a 50 tons/day $\mathrm{H}_{2}$ plant, the total uninstalled capital costs are $\sim 460 \$ / \mathrm{kW}$, with approx. $26 \%$ costs associated with BoP. At the same time, capital costs for a SWRO plant are dependent on technology, location, environmental regulations and most importantly the plant size. ${ }^{27}$ For example, a medium size 10 million gallons per day $\left(37,800 \mathrm{~m}^{3} /\right.$ day $) \mathrm{SWRO}$ plant would cost $\sim 80$ million $\$$, whereas a smaller plant with 0.5 million gallons per day $\left(1890 \mathrm{~m}^{3} /\right.$ day) capacity would cost $\sim 7$ million $\$ .{ }^{40}$ For our case study, we estimated a direct capital cost of $\sim 1.86$ million $\$$ for $500 \mathrm{~m}^{3} /$ day SWRO plant. In contrary to the broad-brushed argument by many in literature, this analysis reveals that the CAPEX of the SWRO plant contributed only $\sim 3 \%$ of total direct CAPEX required for the coupled process (Figure 5(b)). A breakdown of the OPEX for the coupled SWRO-PEM process is shown in Figure 5(c). The OPEX of PEM systems are dominated by electricity costs due to the energy intensive electrolysis process with other contributions from O\&M and stack replacement costs. On the other hand, the typical OPEX for SWRO plants comprises power consumption, membrane replacement, waste stream disposal, chemicals, labor, and O\&M cost. ${ }^{33,41}$ Assuming an electricity cost of 0.05 $\$ / \mathrm{kWh}$, the OPEX of SWRO plant represent a small fraction $(\sim 0.2 \%)$ of the total OPEX for coupled process and is dominated by electricity costs to run the PEM electrolyzer ( $\sim 95 \%)$. To this end, we calculated the levelized cost of $\mathrm{H}_{2}$, which is $\sim 3.81 \$ / \mathrm{kg}$ without considering SWRO, which marginally increases to $\sim 3.83 \$ / \mathrm{kg}$ when cost of SWRO water is accounted for (Figure 5(d)). The analysis reveals that the use of SWRO water does not add any significant cost to the $\mathrm{H}_{2}$ produced, due to the low energy, CAPEX and OPEX for SWRO as compared to PEM electrolysis. 
(a)

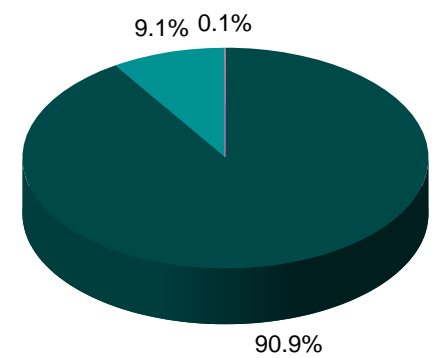

Stack energy requirement

BOP energy requirement

SWRO energy requirement

(c)

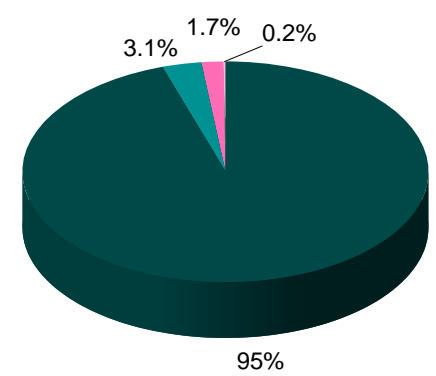

Electrolyser electricity costs Electrolyser O\&M

Electrolyser stack replacement SWRO operating costs (b) Direct capital costs

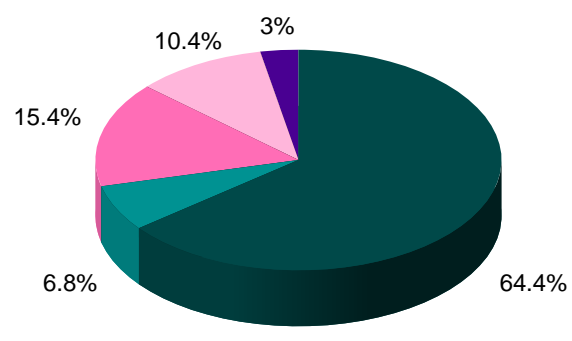

Electrolyzer stack cost

Electrolyzer mechanical BoP

Electrolyzer electrical BoP

Electrolyzer installation cost

SWRO capital costs including installation

(d)

Cost of $\mathrm{H}_{2}$

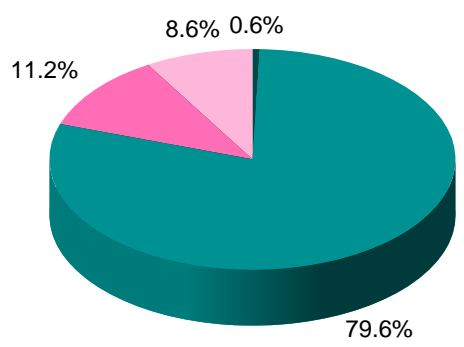

SWRO water cost PEM electricity costs PEM capital costs PEM O\&M + stack replacement costs+staff

Figure 5. Breakdown of the (a) daily energy requirement, (b) total capex, (c) operating costs and (d) levelized cost of $\mathrm{H}_{2}$ for a SWRO-PEM electrolysis plant operating at 50 tons $\mathrm{H}_{2} /$ day capacity.

We further analyzed the carbon footprint of a SWRO facility coupled with PEM electrolysis for $\mathrm{H}_{2}$ production. We ignored any emissions associated with construction and decommissioning as these contributions are minimal when compared to the operating phase of the plant. ${ }^{42}$ We first calculated the $\mathrm{CO}_{2}$ emissions to produce a kilogram of $\mathrm{H}_{2}$ from the SWRO-PEM electrolysis process using the average emission intensities of various energy sources, as shown in Figure 6(a). ${ }^{43}$ One obvious observation is that $\mathrm{H}_{2}$ produced via water electrolysis with purely fossil fuel (coal, oil, natural gas) based electricity would end up producing more $\mathrm{CO}_{2}$ than that of presentday SMR process $\left(8-12 \mathrm{~kg}\right.$ of $\left.\mathrm{CO}_{2} / \mathrm{kg} \mathrm{H}_{2}\right) .{ }^{44}$ Secondly and more importantly the contribution of 


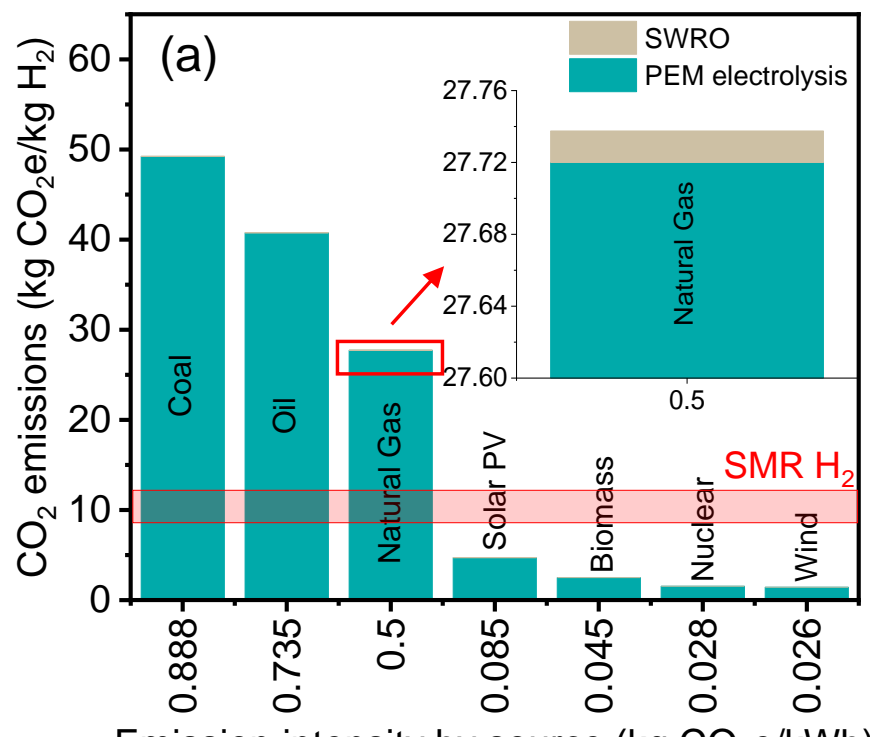

Emission intensity by source $(\mathrm{kg} \mathrm{CO} 2 \mathrm{e} / \mathrm{kWh})$

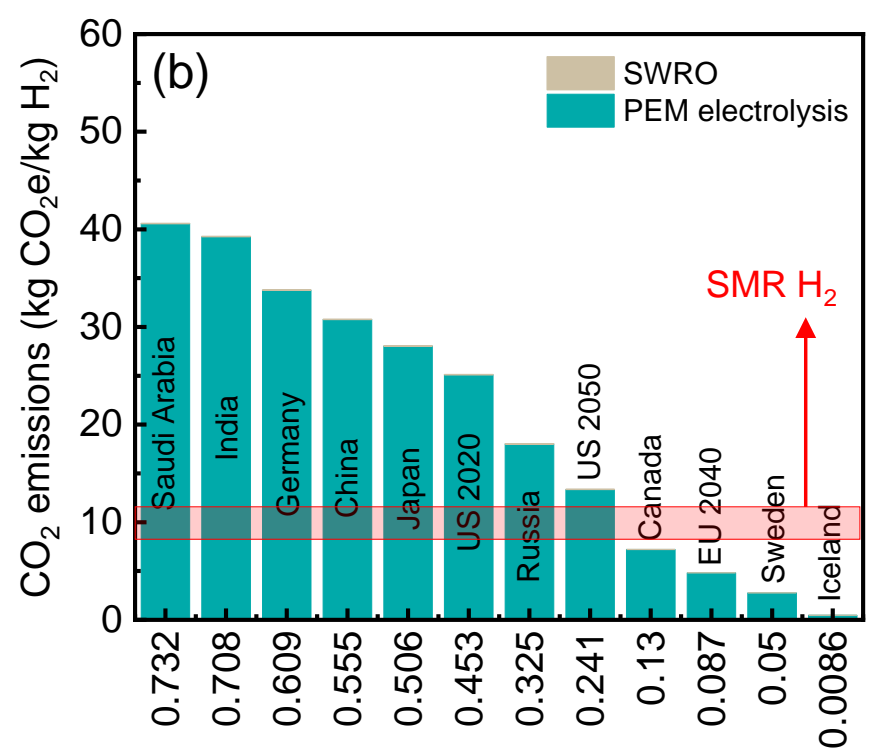

Average carbon footprint $\left(\mathrm{kg} \mathrm{CO}_{2} \mathrm{e} / \mathrm{kWh}\right)$

Figure 6. (a) Summary of $\mathrm{CO}_{2}$ emissions $\left(\mathrm{kg} \mathrm{CO}_{2} \mathrm{e} / \mathrm{kg} \mathrm{H}_{2}\right)$ for $\mathrm{SWRO}-\mathrm{PEM}$ electrolysis process depending on source of electricity ${ }^{43}$, and (b) based on the carbon intensity for electricity generation in various jurisdictions ${ }^{45}$. Inset in (a) shows zoomed view of $\mathrm{CO}_{2}$ emissions from a SWRO-PEM plant using electricity from natural gas power plant. Typical emission from incumbent SMR process is shown with shaded red region. 
SWRO to $\mathrm{CO}_{2}$ emissions is negligibly small when compared to PEM water electrolysis, irrespective of the energy source (Inset of Figure 6(a)).

We also calculated $\mathrm{CO}_{2}$ emissions for the more practical scenario where the SWRO-PEM plant gets its required power from the electricity grid (Figure 3). Figure 6 (b) shows the $\mathrm{CO}_{2}$ emissions from a coupled SWRO-PEM process based on average emission intensity from electricity generation in different jurisdictions. ${ }^{45}$ The analysis indicates the SWRO-PEM process for large scale $\mathrm{H}_{2}$ production is environmentally compelling only in countries with a carbon intensity of electricity $<0.18 \mathrm{~kg} \mathrm{CO} 2 / \mathrm{kWh}$. Today, such low carbon footprint from electricity generation is only possible in countries having significant fraction of their electrical energy from

renewables, such as Canada, Sweden, and Iceland. ${ }^{46}$ In countries like China and the United states which are currently the biggest $\mathrm{CO}_{2}$ emitters in the world, such low carbon intensity would be an ambitious target to achieve in the next couple of decades unless there is a major shift in energy policies and production methods. For truly green $\mathrm{H}_{2}$ production, one could consider the example of Iceland where $100 \%$ renewable electricity on grid emits only $\sim 0.48 \mathrm{~kg}-\mathrm{CO}_{2 \mathrm{e}} / \mathrm{kg} \mathrm{H}_{2}{ }^{47}$

\section{Conclusions and Outlook}

In summary, our analysis shows there are limited economic and environmental incentives for pursuing research and development on today's nascent direct seawater splitting technology as opposed to simply coupling industrially mature SWRO with water electrolysis routes for sustainable $\mathrm{H}_{2}$ production in the foreseeable future. With fast growing multiple challenges in energy, water, environment, food, and health affecting modern society, we will likely be better off prioritizing $R \& D$ investment in technologies that have the greatest chance for widespread deployment in near future, including coupled SWRO and PEM systems. This seems to us a more practical and immediately deployable route than large-scale investments in developing catalysts and systems for direct electrolysis of seawater with all its attendant uncertainties. Despite fast development with great promise for future, PEM electrolysis routes to hydrogen production remains expensive for widespread roll out. Therefore, further investment in R\&D efforts from academia and industry for developing low cost and energy efficiency electrocatalysts is vital for future market growth. With 1.2 billion people around the globe living in areas of physical water scarcity, there are opportunities to further develop energy efficient and economically compelling 
desalination technology. ${ }^{48-50}$ Worldwide, desalination is considered an immediate solution to the problem of water scarcity and quality that will worsen with continued population growth and more prolonged droughts linked to climate change. ${ }^{48}$ Using desalinated water for electrolysis has an added advantage of being able to treat water from a wide variety of sources, such as brackish groundwater, surface water, seawater, and domestic and industrial wastewater. ${ }^{28}$ To make it more affordable and accessible, research efforts should be directed towards improving desalination processes, devising more effective and durable membranes, for example, to produce more water per unit of energy. ${ }^{48}$ There are environmental issues to tackle as well such as the disposal or processing of the concentrated brine, which in addition to being extremely salty also contains treatment chemicals. ${ }^{51}$ In excessive concentrations, they have the potential to negatively affect the marine environment. There are efforts to eliminate wastewater discharge via zero liquid discharge (ZLD) approaches and exploring the potential of high-pressure reverse osmosis (HPRO), among other technologies, to efficiently desalinate hypersaline brines. ${ }^{49}$ Furthermore, in some settings, these brines may be considered as a resource for high value minerals and energy recovery instead of being a waste with discharge constraints. Therefore, we pose these questions: Should we consider realigning our R\&D priorities? Is direct seawater splitting a solution looking for a problem that has already been solved?

\section{Acknowledgement}

The author(s) would like to acknowledge the financial support provided by Canada First Excellence Research Fund (CFREF) at University of Calgary. The authors acknowledge Mr. Puneet Mannan from Innovate Calgary for providing data from Patsnap database.

\section{References}

1. Hydrogen Generation Market. https://www.fortunebusinessinsights.com/industryreports/hydrogen-generation-market-100745.

2. $\quad$ Birol, F., The Future of Hydrogen: Seizing Today's Opportunities. IEA 2019.

3. Idriss, H., Towards Large-Scale Hydrogen Production from Water, What Have We Learned and What Are the Main Research Hurdles to Cross for Commercialization. Energy Technology 2021.

4. Tawiah, P.; Duer, J.; Bryant, S. L.; Larter, S.; O’Brien, S.; Dong, M., $\mathrm{CO}_{2}$ injectivity behaviour under non-isothermal conditions-Field observations and assessments from the Quest CCS operation. International Journal of Greenhouse Gas Control 2020, 92, 102843.

5. $\quad$ van Renssen, S., The hydrogen solution? Nature Climate Change 2020, 10 (9), 799-801.

6. Daiyan, R.; MacGill, I.; Amal, R., Opportunities and Challenges for Renewable Power-to-X. ACS Energy Lett. 2020, 5 (12), 3843-3847 
7. Papadis, E.; Tsatsaronis, G., Challenges in the decarbonization of the energy sector. Energy 2020, 118025.

8. Glenk, G.; Reichelstein, S., Economics of converting renewable power to hydrogen. Nature Energy 2019, 4 (3), 216-222.

9. $\quad$ Schmidt, O.; Gambhir, A.; Staffell, I.; Hawkes, A.; Nelson, J.; Few, S., Future cost and performance of water electrolysis: An expert elicitation study. International Journal of Hydrogen Energy 2017, 42 (52), 30470-30492.

10. Li, X.; Hao, X.; Abudula, A.; Guan, G., Nanostructured catalysts for electrochemical water splitting: current state and prospects. Journal of Materials Chemistry A 2016, 4 (31), 11973-12000.

11. Zeng, K.; Zhang, D., Recent progress in alkaline water electrolysis for hydrogen production and applications. Progress in energy combustion science 2010, 36 (3), 307-326.

12. Buttler, A.; Spliethoff, H., Current status of water electrolysis for energy storage, grid balancing and sector coupling via power-to-gas and power-to-liquids: A review. Renewable Sustainable Energy Reviews 2018, 82, 2440-2454.

13. Carmo, M.; Fritz, D. L.; Mergel, J.; Stolten, D., A comprehensive review on PEM water electrolysis. International journal of hydrogen energy 2013, 38 (12), 4901-4934.

14. https://nelhydrogen.com/wp-content/uploads/2020/03/MC100200400-Brochure-Rev-A.pdf.

15. Burdg, J. Infographic: What water type should I use? https://www.labconco.com/articles/water-

type-

difference\#: :text=Type\%20II\%20\%2D\%20ASTM\%20defines\%20Type,not\%20ultrapure\%20like\%20T ype\%20I.

16. Red, T. Ultra Pure vs Feed Water, Comparing the 4 Types of Laboratory Water.

https://www.technologynetworks.com/immunology/lists/4-types-of-laboratory-water-made-simple293547\#: :text=Also\%20known\%20as\%20general\%20laboratory,electrical\%20ion\%20exchange\%20(E DI).\&text=Water\%20is\%20passed\%20between\%20an,membrane\%20within\%20an\%20EDI\%20cell.

17. Al-Amshawee, S.; Yunus, M. Y. B. M.; Azoddein, A. A. M.; Hassell, D. G.; Dakhil, I. H.; Hasan, H. A., Electrodialysis desalination for water and wastewater: A review. Chemical Engineering Journal 2020, 380, 122231.

18. Dresp, S.; Dionigi, F.; Loos, S.; Ferreira de Araujo, J.; Spöri, C.; Gliech, M.; Dau, H.; Strasser, P., Direct electrolytic splitting of seawater: activity, selectivity, degradation, and recovery studied from the molecular catalyst structure to the electrolyzer cell level. Advanced Energy Materials 2018, 8 (22), 1800338.

19. Dresp, S. r.; Dionigi, F.; Klingenhof, M.; Strasser, P., Direct electrolytic splitting of seawater: opportunities and challenges. ACS Energy Letters 2019, 4 (4), 933-942.

20. Coro, G.; Trumpy, E., Predicting geographical suitability of geothermal power plants. Journal of Cleaner Production 2020, 267, 121874.

21. Goosen, M.; Mahmoudi, H.; Ghaffour, N., Water desalination using geothermal energy. Energies 2010, 3 (8), 1423-1442.

22. MacFarlane, D. R.; Cherepanov, P. V.; Choi, J.; Suryanto, B. H.; Hodgetts, R. Y.; Bakker, J. M.; Vallana, F. M. F.; Simonov, A. N., A roadmap to the ammonia economy. Joule 2020.

23. Tong, W.; Forster, M.; Dionigi, F.; Dresp, S.; Erami, R. S.; Strasser, P.; Cowan, A. J.; Farràs, P., Electrolysis of low-grade and saline surface water. Nature Energy 2020, 5 (5), 367-377.

24. Dionigi, F.; Reier, T.; Pawolek, Z.; Gliech, M.; Strasser, P., Design criteria, operating conditions, and nickel-iron hydroxide catalyst materials for selective seawater electrolysis. ChemSusChem 2016, 9 (9), 962-972.

25. Association, A. M. T., Membrane desalination power usage put in perspective.

https://www.amtaorg.com/wp-

content/uploads/07_Membrane_Desalination_Power_Usage_Put_In_Perspective.pdf 2016.

26. Ghaffour, N.; Lattemann, S.; Missimer, T.; Ng, K. C.; Sinha, S.; Amy, G., Renewable energydriven innovative energy-efficient desalination technologies. Applied Energy 2014, 136, 1155-1165. 
27. Ghaffour, N.; Missimer, T. M.; Amy, G. L., Technical review and evaluation of the economics of water desalination: current and future challenges for better water supply sustainability. Desalination 2013, 309, 197-207.

28. Lattemann, S.; Kennedy, M. D.; Schippers, J. C.; Amy, G., Global desalination situation. Sustainability Science Engineering 2010, 2, 7-39.

29. Shatat, M.; Worall, M.; Riffat, S., Opportunities for solar water desalination worldwide. Sustainable cities society 2013, 9, 67-80.

30. No Water, No Life. https://www.acwapower.com/news/no-water-no-life/.

31. Amy, G.; Ghaffour, N.; Li, Z.; Francis, L.; Linares, R. V.; Missimer, T.; Lattemann, S., Membrane-based seawater desalination: Present and future prospects. Desalination 2017, 401, 16-21.

32. Global Water Intelligence Report, https://www.globalwaterintel.com, (2020-2021).

33. Bank, W., The Role of Desalination in an Increasingly Water-Scarce World. World Bank: 2019.

34. Peterson, D.; Vickers, J.; DeSantis, D., Hydrogen production cost from PEM electrolysis-2019. DOE Hydrogen Fuel Cells Program Record 190092020.

35. Gulch, C. Sterling: New reverse osmosis water treatment plant online and ramping up to full production. https://coyotegulch.blog/2013/01/06/sterling-new-reverse-osmosis-water-treatment-plantonline-and-ramping-up-to-full-production/.

36. Kim, Y. M.; Kim, S. J.; Kim, Y. S.; Lee, S.; Kim, I. S.; Kim, J. H., Overview of systems engineering approaches for a large-scale seawater desalination plant with a reverse osmosis network. Desalination 2009, 238 (1-3), 312-332.

37. Harvey, N. J.; Ur Rehman, Z.; Leiknes, T.; Ghaffour, N.; Urakawa, H.; Missimer, T. M., Organic compounds and microbial assessment of a seawater reverse osmosis facility at Tampa Bay Water, USA. Desalination 2020, 496, 114735.

38. https://www.gulp.ie/2020/09/10/what-is-reverse-osmosis/.

39. Jones, E.; Qadir, M.; van Vliet, M. T.; Smakhtin, V.; Kang, S.-m., The state of desalination and brine production: A global outlook. Science of the Total Environment 2019, 657, 1343-1356.

40. Wilf, M.; Awerbuch, L., The guidebook to membrane desalination technology: reverse osmosis, nanofiltration and hybrid systems: process, design, applications and economics. Balaban Desalination Publications: 2007.

41. Im, S. J.; Jeong, S.; Jeong, S.; Jang, A., Techno-economic evaluation of an element-scale forward osmosis-reverse osmosis hybrid process for seawater desalination. Desalination 2020, 476, 114240 .

42. Plappally, A., Energy requirements for water production, treatment, end use, reclamation, and disposal. Renewable Sustainable Energy Reviews 2012, 16 (7), 4818-4848.

43. WNA Report, Comparison of Lifecycle Greenhouse Gas Emissions of Various Electricity Generation Sources; http://www.worldnuclear.org/uploadedFiles/org/WNA/Publications/Working_Group_Reports/comparison_of_lifecycle.pdf, 2011.

44. Alsayegh, S.; Varjian, R.; Alsalik, Y.; Katsiev, K.; Isimjan, T.; Idriss, H., Methanol Production Using Ultrahigh Concentrated Solar Cells: Hybrid Electrolysis and CO2 Capture. ACS Energy Letters 2020, 5 (2), 540-544.

45. Footprint, C., Country specific electricity grid greenhouse gas emission factors.

https://www.carbonfootprint.com/docs/2020_06_emissions_factors_sources_for_2020_electricity_v1_1.p df 2019.

46. Deutz, S.; Bardow, A., Life-cycle assessment of an industrial direct air capture process based on temperature-vacuum swing adsorption. Nature Energy 2021.

47. Installed Electrical Capacity and Electricity Generation of Geothermal Power Plants in Iceland 1969-2019. https://orkustofnun.is/gogn/Talnaefni/OS-2020-T006-01.pdf.

48. Elimelech, M.; Phillip, W. A., The future of seawater desalination: energy, technology, and the environment. Science 2011, 333 (6043), 712-717. 
49. Davenport, D. M.; Deshmukh, A.; Werber, J. R.; Elimelech, M., High-pressure reverse osmosis for energy-efficient hypersaline brine desalination: current status, design considerations, and research needs. Environmental Science Technology Letters 2018, 5 (8), 467-475.

50. Ghaffour, N.; Soukane, S.; Lee, J.-G.; Kim, Y.; Alpatova, A., Membrane distillation hybrids for water production and energy efficiency enhancement: A critical review. Applied Energy 2019, 254, 113698.

51. Kumar, A.; Phillips, K. R.; Thiel, G. P.; Schröder, U.; Lienhard, J. H., Direct electrosynthesis of sodium hydroxide and hydrochloric acid from brine streams. Nature Catalysis 2019, 2 (2), 106-113. 